\title{
Research on Curriculum System of Electrical Engineering Based on Innovation and Entrepreneurship Education
}

\begin{abstract}
Gao Xin*
College of Electrical Engineering, SMU, Chengdu, Sichuan, China

*gxin7993@163.com

ABSTRACT

The aim of innovation and entrepreneurship education is to cultivate innovation and entrepreneurship talents. Taking Electrical Engineering Specialty as an example, this paper analyzes the current situation and existing problems of innovation and entrepreneurship education, and presents the necessity and principles of constructing the curriculum system of innovation and Entrepreneurship Education for Electrical Engineering Specialty. The curriculum system is based on the requirements of engineering professional certification and personnel training, the four platforms (General Education Platform, disciplinary (professional) basic education platform, professional education platform, innovative and entrepreneurial education practice teaching platform) link up and are closely related to each other, integrating innovative and entrepreneurial ideas into professional education, running through the whole process of innovation and Entrepreneurship Education for college students. The research on the curriculum system of innovation and Entrepreneurship Education for electrical engineering specialty is helpful to enhance the innovation spirit and entrepreneurship ability of college students.
\end{abstract}

Keywords: Innovation and entrepreneurship education, Engineering professional certification, Curriculum system, Electrical Engineering

\section{创新创业教育视域下电气工程及其自动化专业 课程体系的研究}

\author{
高心*
}

西南民族大学电气工程学院, 成都, 四川, 中国

*gxin7993@163.com

\begin{abstract}
摘要
创新创业教育的目的是培养和造就创新创业型人才。本文以电气工程及其自动化专业为例, 分析了目前创新创 业教育的现状和存在的问题，提出了构建电气工程及其专业创新创业教育课程体系的必要性及其原则。该课程 体系以工程专业认证和人才培养需求为导向，四个平台（通识教育平台、学科（专业）基础教育平台、专业教 育平台、创新创业教育实践教学平台) 相互衔接、密切关联，把创新创业理念融入专业教育中，贯穿大学生创 新创业教育全过程。电气工程及其专业创新创业教育课程体系的研究有助于增强大学生创新精神和创业能力。
\end{abstract}

关键词: 创新创业教育; 工程专业认证; 课程体系; 电气工程及其自动化专业 


\section{1. 引言}

创新创业是我国经济发展的重要引擎和推动力, 开展大学生创新创业教育, 是高等教育改革和发展发 展的需要。教育部在《关于大力推进高等学校创新创 业教育和大学生自主创业工作的意见》中指出:"在高 等学校开展创新创业教育, 积极鼓励高校学生自主创 业, 是教育系统深人学习实践科学发展观, 服务于创 新型国家建设的重大战略举措; 是深化高等教育教学 改革, 培养学生创新精神和实践能力的重要途径; 是 落实以创业带动就业, 促进高校毕业生充分就业的重 要措施"。培养具有创新创业理念的电气工程人才的 重要途径是构建符合人才培养所需的电气工程专业 创新创业教育课程体系。课程体系是高等教育实现 培养目标的载体, 对体现专业教育理念, 展现课程设 置, 提升学生专业素养有着十分重要的作用 ${ }^{[1]}$ 。

电气工程学科是现代高科技领域的核心学科之 一, 更是当今高新技术领域不可或缺的关键学科 ${ }^{[2]}$ 。 它以其强弱结合的突出特点成为广大学生青睐的工 科专业。随着国家工程专业认证的持续推进, 为高校 培养具备高素质创新创业电气工程人才提供了坚强 的保证。

近年来电气工程专业人才的培养取得了显著成 效, 但各高校在开展创新创业教育工作中尚存在一些 问题 ${ }^{[3]}$, 例如, 创新创业课程设置不够合理; 符合工 程专业认证要求的创新创业教育与专业教育联系不 够紧密, 创新创业教育课程体系尚不完善; 双创双师 型教师不足, 校企合作缺乏动力, 学生校外实习效果 不理想等。这些问题无疑限制了电气工程专业学生创 新创业理念和能力的提高。

本文基于电气工程及其自动化专业特点, 从电气 工程及其自动化专业创新创业教育人才培养中存在 的问题出发, 介绍了构建电气专业创新创业教育课程 体系的必要性及其原则, 重点阐述了创新创业教育如 何有机融入专业教育和实践教育中。研究成果对提升 大学生创新创业综合素质和综合能力, 完善本科专业 培养方案具有一定的理论参考价值。

\section{2. 电气工程及其自动化专业及课程特点}

电气工程及其自动化专业是电气信息领域的一 门综合性较强的学科。专业的特点是强弱电结合、系 统与元件结合、电工技术与电子技术结合、机电结合。 专业以控制理论和电力网络理论为基础, 以电力电子 技术、电气控制技术、计算机技术信息与网络技术和 机电一体化技术为主要技术手段, 涉及系统分析、系 统设计、系统开发和系统管理与决策等研究领域。主 要研究方向包括电力系统及其自动化, 高电压与绝缘 技术, 电力电子与电气传动、电机运行与控制、电工 新技术。培养和造就宽口径、复合型、应用型高级工 程技术人才。
电气工程及其自动化专业学科基础课程的特点: 电路分析 (电网络理论基础)、模拟电路 (认识半导体 元件)、数字电路 (01 的世界)、自动控制原理（最抽 象的课程)、电磁场 (更上一层楼的课程)、信号与系 统 (充满数学运算的课程)、数字信号处理 DSP (实 用性课程)和软件控制硬件的程序设计 $\mathrm{C}$ 语言及微机 原理、单片机课程。

电气工程及其自动化专业基础课程的特点: 电气 工程概论 (入门课程)、电机学 (理论性实践性时空观 强的基础课程)、电力电子技术 (强弱电结合课程)、 电力系统分析 (基础理论与专业理论的桥梁课程)。

电气工程及其自动化专业课程的特点: 电力系统 继电保护原理 (强电核心课程)、发电厂电气部分 (课 程设计先导课程)、电网调度自动化 (强电智能课程)、 高电压与绝缘技术 (试验性课程)。

电气工程及其自动化专业实践性课程: 电气照明 技术、供配电系统、建筑电气、工厂供电、课程设计、 课程实习、毕业实习、毕业设计。

\section{3. 电气工程及其自动化专业创新创业教育 存在的问题}

要提高大学生的创新创业能力, 形成良好的创新 创业教育氛围，需构建一个全方位的创新创业培育体 系, 形成一个像生态体系一样的良性循环系统。这一 体系包括高校、政府、企业、学生等多个子系统, 各 子系统之间相互联系、相互作用、相互支撑，构成一 个完整的创新创业教育培育体系。下面就高校、企业、 学生等几个层面阐述存在的问题。

学校: 随着 “互联网+”、电商营销的迅速发展, 学校对企业管理、市场营销、法律、电子信息技术、 计算机技术、大数据等技术的创新创业的支持力度加 大, 而对以强电为主的电气工程专业的创新创业还未 给予足够重视, 该专业教师和学生参与创新创业活动 的积极性有待进一步增强。

学生: 由于本专业就业普遍较好, 除了考研和保 研学生要求创新活动分, 积极参加创新创业活动并争 取获奖外, 大多数学生满足于能顺利毕业而后就业, 对参加创新创业活动的积极性不高, 创新活动真正受 益的学生较少。创新比赛获奖成了部分考研和保研学 生追求的目标, 没有认识到创新创业的内涵。由于缺 乏创新创业教育宣传和引导, 学生对创新创业的认识 尚有偏差, 创业信心不足。

教师: 学历层次高, 但大多数教师是从学校到学 校, 很少有企业工作和创业经验, “双创型” 教师缺 之, 专业教师多是在校内从事理论教学和实践教学, 很少有在校外创业或在企业顶岗锻炼。由于教师创新 创业能力有限, 要培养出高素质创新创业人才实为不 易。

企业：出于安全生产的考虑和行业的有关规定, 电力企业并不热衷接纳学生实习, 即使允许实习, 也 
限于是浏览参观, 达不到理论与实践相结合的实习效 果。此外，企业从校企合作中也并未获得所期望的效 益，校企合作也就仅仅成为参观实习合作，其合作效 果大打折扣, 企业动力不足, 其原因与高校科研成果 转化不够, 不能很好地解决企业实际问题等因素有关。

课程体系: 近年来, 高校为推进工程教育改革和 “新工科”建设, 实施了工程教育专业认证, 该认证 是国际通行的工程教育质量保障制度, 也是实现工程 教育国际互认和工程师资格互认的重要基础。工程教 育专业认证要求专业课程体系设置、师资队伍配备、 办学条件配备等都要围绕学生毕业能力达成这一核 心任务展开, 保证工科人才培养质量。但由于大部分 高校还未获准国家工程教育专业认证, 且双创教育起 步较晚, 构建具有工程教育认证背景下的创新创业教 育课程体系相对滞后。

从以上五个层面反映出的问题可见, 课程体系的 构建是解决以上问题的有效途径, 完善的课程体系建 设将有助于学校各职能部门出台相应的政策和改革 措施。

\section{4. 构建电气工程及其自动化专业创新创业 教育课程体系的必要性和原则}

电气工程及其自动化专业是在原电力系统及其 自动化、电机电器及其控制、高电压与绝缘技术和电 气技术四个专业合并组成, 该专业体现了 “宽口径、 厚基础、强能力、高素质” 的人才培养原则。由于各 高校自身发展和办学条件存在差异, 有的高校侧重于 电力系统及其自动化, 有的偏向于电机运行与控制和 高电压与绝缘技术。因此, 如何基于自身办学目标和 办学条件, 构建系统性、特色鲜明的课程体系, 是电 气工程及其自动化专业培养合格电气工程应用型人 才的关键。在新形势下, 构建电气工程及其自动化专 业创新创业教育课程体系尤其更为必要和迫切。下面 本文将对构建电气工程及其自动化专业创新创业教 育课程体系的必要性和构建的原则进行阐述。

\section{1. 必要性}

电气工程及其自动化专业创新创业教育尚处于 起步阶段, 创新创业教育理念不成熟, 仅仅是围绕学 科竞赛、创新设计类竞赛等创新活动进行重复性训练, 而忽视创新理念、创新意识的培养及创新能力的提升; 创新创业教育与专业教育融合不够, 在专业课程教学 中缺乏创新创业教育理念的导入。虽然各高校开设了 创新创业教育课程, 但课程设置大都与专业脱节, 不 能有效贯穿本科四年创新创业教育全过程。因此, 为 了培养具有创新创业意识和能力的应用型工科人才, 有必要构建工程教育认证背景下的电气工程及其自 动化专业创新创业教育课程体系, 从而有助于高校各 职能部门出台相应的政策和改革措施。

\section{2. 原则}

构建电气工程专业创新创业教育课程体系应将 电气工程及其自动化专业特点和课程优化及创新创 业教育实践高度结合在一起。在遵循 “厚基础、宽口 径、强弱结合、课程模块化” 的课程体系总原则下, 突出理论与实践相结合、创新创业教育与符合工程专 业认证的专业教育相结合、创新创业教育全程化与学 生个性化发展相结合。理论与实践相结合就是指理论 知识的教学要与实践教学紧密结合, 使学生在理论与 实践的结合中理解和掌握理论知识, 并通过实践培养 学生运用理论知识的能力; 创新创业教育与符合工程 专业认证的专业教育相结合指的是课程设置必须以 工程专业认证为导向, 有目的地将创新创业教育知识 和理念渗透到专业课教学中, 以此丰富学生创新创业 的专业知识结构, 提高学生的创新创业能力; 创新创 业教育全程化是指创新创业课程体系应有效贯穿本 科创新创业教育全过程, 自始自终地强化学生创新创 业意识与素养, 提升其创新创业技能。以上原则不仅 强化学生对本专业理论知识掌握, 而且突出创新创业 教育在专业人才培养的作用。

\section{5. 电气工程及其自动化专业创新创业教育 课程体系}

根据构建电气工程及其自动化专业创新创业教 育课程体系原则, 电气工程及其自动化专业创新创业 教育课程体系由四个平台组成: 通识教育平台、学科

（专业）基础教育平台、专业教育平台、创新创业教 育实践教育平台。各平台学分分配: 通识教育平台 38 学分, 学科 (专业) 基础教育平台 (含实验) 48 学分, 专业教育平台 (含实验) 37 学分, 创新创业教育实践 教育平台 42 学分。本文重点介绍如何将全程化创新 创业教育融入电气工程及其自动化专业课程体系。

通识教育平台: 传统的通识教育课程设置, 一般 缺乏增强科学精神与人文精神互相交融的通识课程 及创新创业基础课程 [4]。通识课程中专设创新创业类 模块, 该模块包括通识必修课程、通识选修课程。通 识必修课程除了职业生涯与发展规划及就业指导课 外, 增加《创新创业概论》课程, 聘请有丰富双创经 验的企业家和教师授课, 系统学习创新原理、创新内 外环境、创新思维和创新能力及其训练、创业机会、 创业计划、创业风险等创新创业基础知识, 指导学生 制定职业生涯规划, 明确未来发展方向, 激发学生创 新创业意识; 通识选修课程开设创新方法与应用

（TRIZ）、大学生创业基础、工程创新方法论、创业 管理、专利、法律等课程。专设通识课程创新创业类 模块不仅指导学生了解创新创业有关知识, 奠定学生 创新创业基础, 激发学生创新创业梦想。而且可有效 避免创新创业类课程流于形式, 学生为凑学分而随意 选择课程的现象。

学科 (专业) 基础教育平台: 该平台注重理论与 实践的结合。在系统学习学科基础课程, 如电路原理、 
模数电路、集成电路、C 语言、微机原理与接口技术、 电路工艺实践等课程基础上，增设《电子电路创新型 综合设计》课程, 聘请校内优秀双创指导教师授课。 课程设计按照大创计划、学科竞赛的要求完成给定设 计题目, 培养学生创新能力和实际动手能力。该课程 设计不仅可扩大学生参与创新活动的覆盖面, 让更多 的学生能接受严格的规范的创新训练, 而且指导教师 可从中遴选出具有创新创业潜质、团队协作精神、动 手能力较强的学生, 组成创新团队, 参加各级各类电 子设计大赛、智能汽车大赛等学科竞赛。此外, 该课 程设计优秀者可冲抵创新创业学分。

专业教育平台: 以工程专业认证为导向, 将创新 创业教育有机融入专业教育中, 其有效途径是建立专 业课程群。课程群是由承担不同任务, 内容上有不同 特点且密切相关、相承和渗透, 具有互补性的几门系 列课程组合而成的有机整体 [5]。通过将符合工程专业 认证的有交叉、渗透的课程构建课程群, 结合实验和 企业实际案例实现专业课程与创新创业教育的融合。 构建的四个课程群: 电机学 + 电力拖动基础 + 电力电子 与电气传动技术 + 实验 + 课程设计, 电力系统分析 + 电 网调度自动化系统 + 电力系统继电保护基本原理 + 电 力系统稳定与控制+实验+课程设计, 工厂供电 + 楼宇 自动化技术 + 电气照明技术 + 供配电自动化系统 + 实验 +课程设计, 光伏发电技术 + 风力发电技术 + 水力发电 技术+光风互补发电技术+实验+课程设计。四个课程 群也就构成了电气工程及其自动化专业的四个研究 方向。专业课程群的建立, 不仅专业课程的设置合理 清晰, 而且为学生今后实习、就业、创业、考研提供 了明确的专业方向, 有利于学生有目的地选择对自己 创新创业感兴趣的课程 (群), 提高学生专业素养, 激 发学生创新创业热情。

创新创业教育实践教育平台一一该平台以提高 学生专业技能, 了解企业, 明确就业、创业、考研意 愿和确定毕业后职业发展方向为目标。为深化创新创 业教育, 该平台开设 $\mathrm{KAB}$ 创业基础、电气工程实训 以及工程专业认证要求的金工实习、生产实习、毕业 实习、毕业设计等课程。《KAB 创业基础》课程采用 三阶段教学模式 (KAB: Know About Business, 了解 企业, 是国际劳工组织为培养的学生的创业意识和创 业能力而专门开发的教育项目)。第 1 阶段：电力行 业调查实践。要求学生深入电力企业, 了解企业生产、 行业发展情况, 了解企业对毕业生的需求情况, 撰写 行业调查报告; 第 2 阶段, 邀请本行业具有丰富双创 经验的优秀校友或企业家到校为学生举办创新创业 专题讲座或报告会, 要求学生撰写心得体会; 第 3 阶 段: 聘请具有丰富双创经验的校内外教师授课, 重点 对创业中的商业计划做专门的讲授。在教师的指导下， 按照创业要求, 撰写商业计划书 (内容包括: 经营目 标、产品与服务、市场分析、商业模式、经营计划与 管理和运作、风险及制约因素分析等)。教师根据学 生撰写的行业调查报告、心得体会、商业计划书考核 评价, 成绩优秀者可冲抵创新创业学分。毕业设计环
节实行创新设计类和创业类两项选题。创新设计类选 题来自教师的科研课题或学生自拟题目, 提交毕业设 计论文; 而创业类选题来自于有创业意愿的学生, 学 生需提交创业计划书和相关材料, 创业计划书评为优 秀者, 可冲抵创新创业学分。创新创业课程的开设, 既丰富学生专业知识, 又让学生懂得创新思维的重要 性，并对创业方式及专业发展方向有了更直观的理解。

创新创业教育课程体系旨在建立和完善以创业 为导向的人才培养机制, 着力解决课程设置不合理, “重学轻能”现象, 有效地实现从大一到大四全程化、 不间断的创新创业教育, 其构架如图 1 所示。以大一 阶段《创新创业概论》课程为起点, 引导学生了解创 新创业基本知识, 培养创新创业意识; 大二阶段结合 所学 “三电” 课程, 尝试电子电路创新型综合设计, 并开展大创项目实战训练, 提高学生应用所学知识能 力和动手实践能力; 大三阶段结合所学专业知识从事 专业课程设计, 参加各级各类学科竞赛, 如电子设计 大赛、数学建模竞赛和机器人智能小车等竞赛, 并通 过行业市场调研, 了解就业市场前景, 为大四阶段的 学习、就业及创新创业能力提升, 打下坚实的基础; 大四阶段以就业为导向, 通过企业实习和 $\mathrm{KAB}$ 创业 基础课程的实际锻炼, 以毕业设计为考核手段, 实现 创新引领创业, 创业带动就业的人才培养目标。

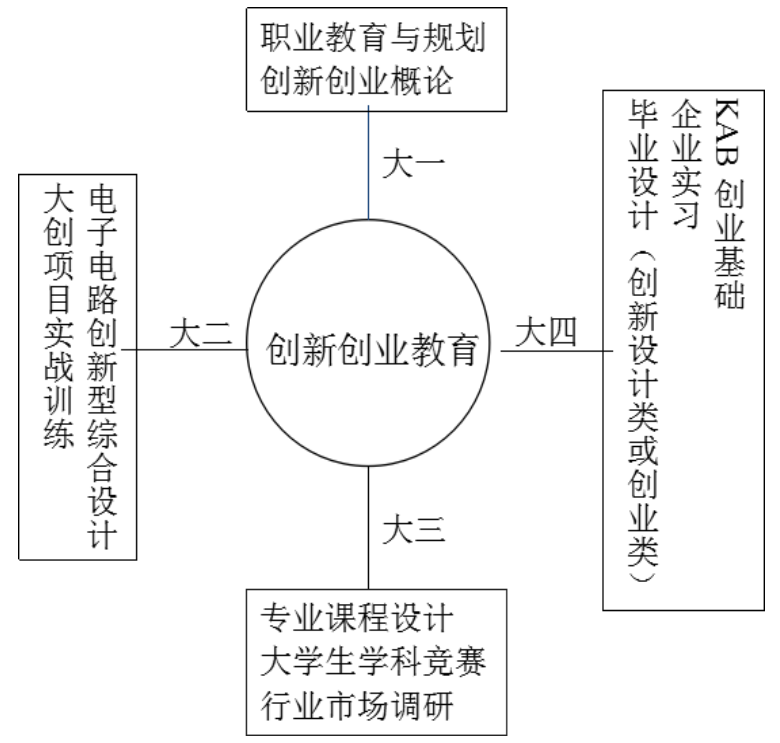

图 1全程化创新创业教育课程构架

以上各平台的教学与实践依赖于过硬的 “双创型 师资队伍和完善的校内外实习实训基地。加快培养富 有创新精神、敢于投身实践的创新创业人才队伍是实 现人才培养目标的关键。各高校应从服务教学改革、 教学管理第一线需要, 建立和完善教学评价体系和 “双创型”教师培养机制。

\section{6. 结论}

创新创业教育已纳入我国创新发展的重要战略 层面, 在高校开展创新创业教育意义重大。本文以国 家工程专业认证为导向, 构建了电气工程专业创新创 
业教育课程体系。课程体系对四个平台的组成、课程 的设置做了系统的研究，研究成果对完善该专业本科 培养方案具有一定的理论和实践参考价值。

\section{REFERENCES}

[1] Yong, M. (2017) Research on curriculum system of innovation and entrepreneurship education. Education and Teaching Forum. 49: 33-34

[2] Jiang, L.Y. (2015) On the path of innovation and entrepreneurship education for electrical speciality. Cultural and Educational Materials. 22: 138-139

[3] Yu, S.J. (2016) Research on innovation and entrepreneurship education reform of electrical engineering and automation professionals under the new situation. Technology and Innovation. 19: 3-4

[4] Xin, J. (2016) Electrical college students' innovation and entrepreneurship ability training. Shandong Industrial Technology. 20:216-218

[5] Liu, H., Ran, Y. (2014) The connotation of curriculum group and its related concepts. Journal of Hubei Correspondence University. 5:120-121 